Research Article

\title{
Experimental Verification of the Weibull Distribution in a Reverberation Chamber
}

\author{
Jianhua Xu, ${ }^{1,2}$ Yongjiu Zhao, ${ }^{1}$ and Qian Xu ${ }^{1}{ }^{1}$ \\ ${ }^{1}$ College of Electronic and Information Engineering, Nanjing University of Aeronautics and Astronautics, Nanjing 211106, China \\ ${ }^{2}$ The 41st Institute of China Electronics Technology Group Corporation, Qingdao 266555, China \\ Correspondence should be addressed to Qian Xu; emxu@foxmail.com
}

Received 24 May 2019; Revised 28 June 2019; Accepted 19 July 2019; Published 7 August 2019

Academic Editor: Mauro Parise

Copyright (c) 2019 Jianhua Xu et al. This is an open access article distributed under the Creative Commons Attribution License, which permits unrestricted use, distribution, and reproduction in any medium, provided the original work is properly cited.

A Weibull distribution has been proposed for the probability density function (PDF) of the magnitude of the E-field in a reverberation chamber (RC). However, the Weibull distribution has two parameters, and if the parameters are position sensitive, the use of the Weibull distribution could be very limited. We investigate the sensitivity of the estimated parameters of the Weibull distribution in this study; the measurement results show that the parameters of the Weibull distribution depend on the positions of the antenna (or device under test), but not sensitive, and the statistical behavior of the parameters can be quantified. This means that the model of the Weibull distribution has a wider usable frequency range than that of the Rayleigh distribution and the statistical variation of the parameters needs to be considered.

\section{Introduction}

Reverberation chambers (RCs) have been widely used in the electromagnetic compatibility (EMC) test and over-the-air (OTA) measurement [1-6]; the electrical field inside an RC in the working volume is statistically uniform, and this provides the foundation of the applications of the RC [2]. However, the RC has to work in the overmoded region to satisfy the statistical distribution model (Rayleigh distribution). It is well known that when the resonant modes (or incident waves) increase, the E-field distribution approaches the Rayleigh distribution $[2,3]$. When the $\mathrm{RC}$ works in the undermoded region, the Weibull distribution is more applicable than the Rayleigh distribution [3].

The Weibull distribution has been verified at a specific antenna position [7-11]; the measurement results show that the Weibull distribution parameters for different polarized E-fields seem quite stable in a very wide frequency range [9], but the position sensitivity of the parameters has not been studied. If the parameters of the Weibull distribution are very sensitive to the positions in an RC, they will limit the application of the model and the behavior of the RC could be very difficult to characterize.

To investigate this problem, we measure the $S$-parameters in an $\mathrm{RC}$ at different positions and use the maximum likelihood estimate (MLE) method to obtain the parameters of the Weibull distribution. Section 2 provides the theory and the setup of the measurement, Section 3 analyzes the measurement results, and Section 4 summarizes the paper.

\section{Theory and Measurement Setup}

The Weibull distribution has been introduced to the RC in $[3,7-11]$, and its probability density function (PDF) is

$$
f_{\text {Weibull }}(X ; a, b)=a b x^{b-1} \exp \left(-a x^{b}\right), \quad x \geq 0,
$$

where $a$ is called the scale parameter and $b$ is the shape parameter. Note that when $a=\pi / 4$ and $b=2$, the Weibull distribution reduces to the normalized Rayleigh distribution: 


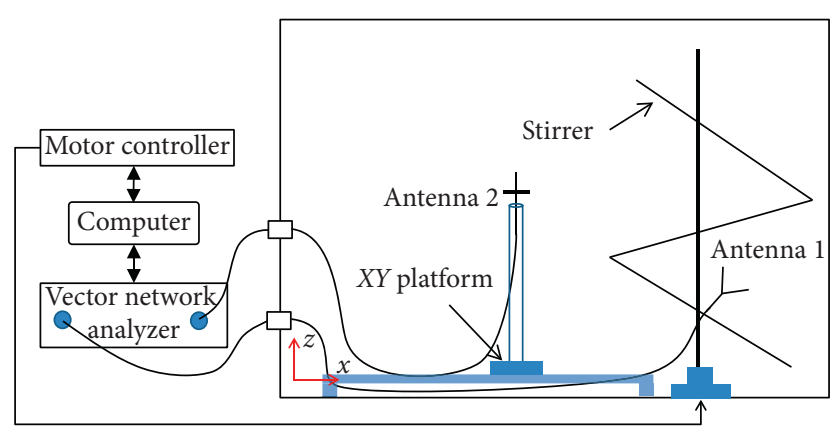

(a)

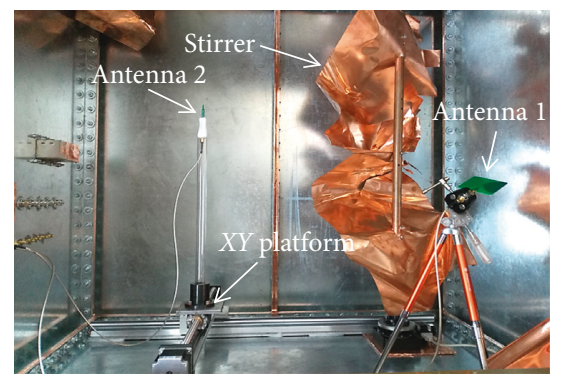

(b)

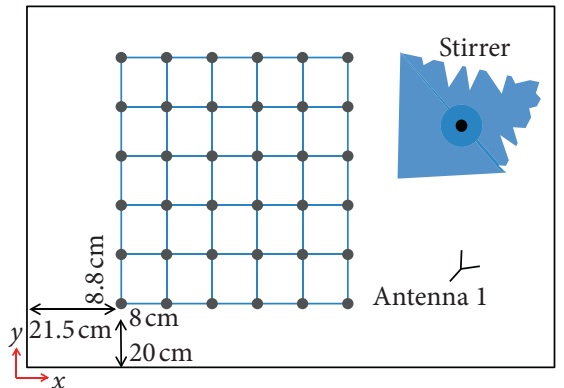

(c)

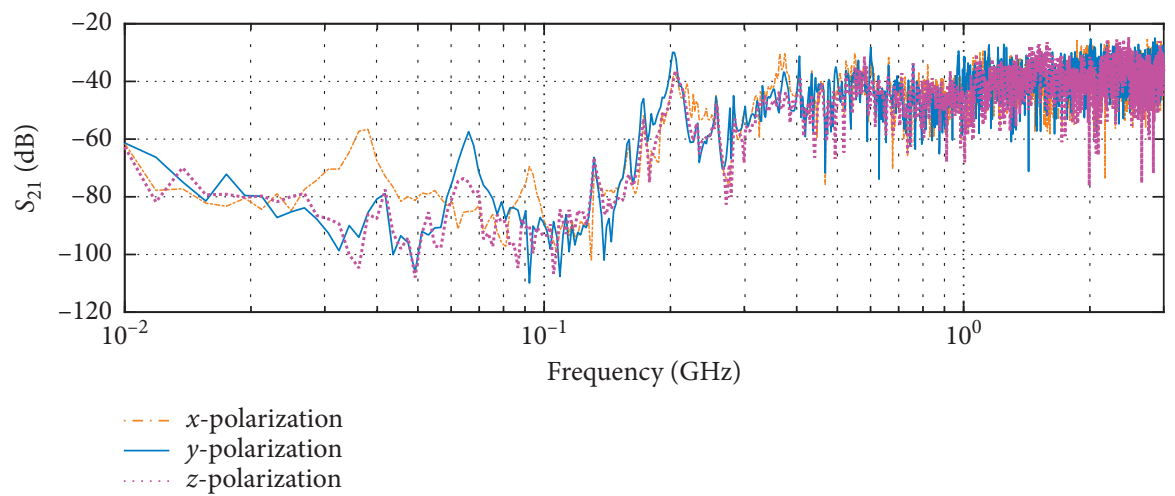

(d)

FiguRE 1: (a) Schematic plot of the measurement. (b) Measurement scenario: the dimensions of the RC are $0.8 \mathrm{~m} \times 1.2 \mathrm{~m} \times 1.2 \mathrm{~m}$; a plastic tube is used to support antenna 2. (c) Measurement positions of antenna 2 in the $X Y$ plane, and three different heights were measured: $30 \mathrm{~cm}$, $62 \mathrm{~cm}$, and $98 \mathrm{~cm}$. (d) Typical measured $S_{21}$ at one probe position with three polarizations.

$$
f_{\text {Rayleigh }}(X)=\frac{\pi x}{2} \exp \left(-\frac{\pi x^{2}}{4}\right), \quad x \geq 0,
$$

where $X$ is the random variable normalized to the mean value; when $a=1$ and $b=1$, the Weibull distribution reduces to the normalized exponential distribution [8]:

$$
f_{\operatorname{Exp}}(X)=\exp (-x), \quad x \geq 0 .
$$

Thus, the Weibull distribution is more general than the Rayleigh distribution (or exponential distribution). By applying the MLE method, the estimated parameters $(a, b)$ can be found as the solution of the equation system [3]: 


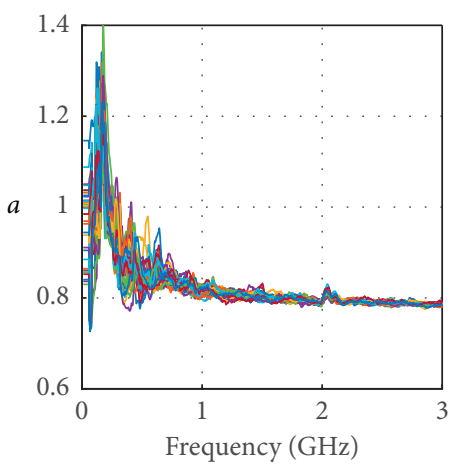

(a)

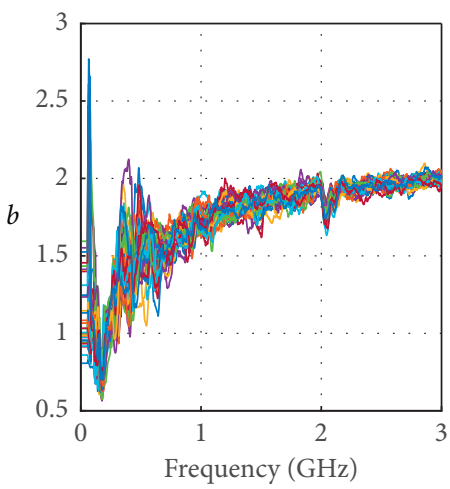

(d)

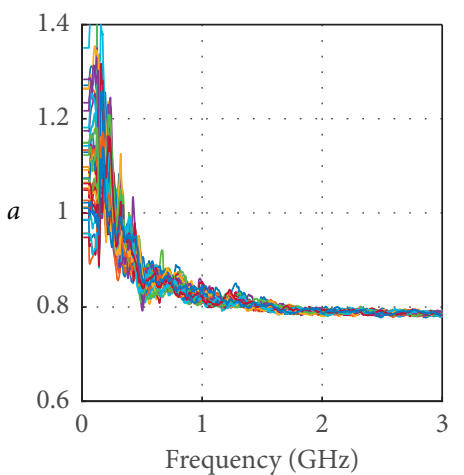

(g)

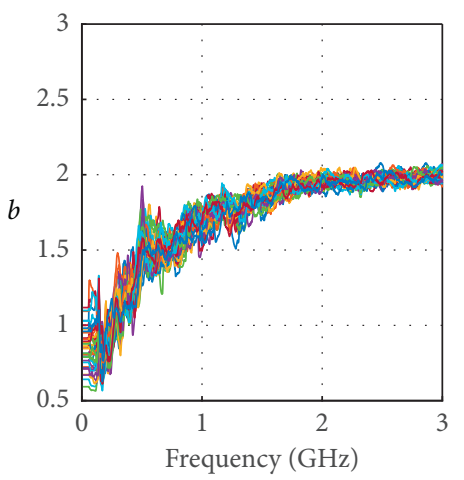

(j)

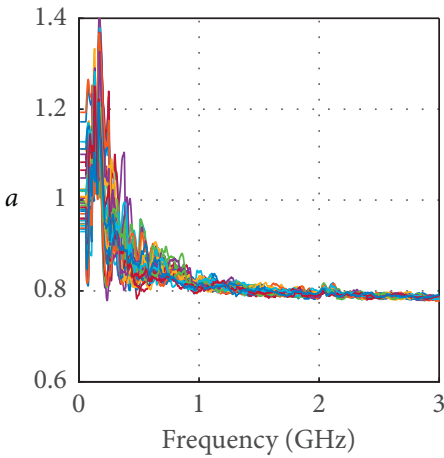

(b)

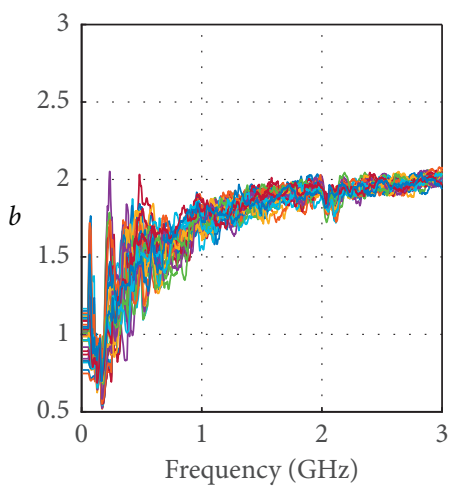

(e)

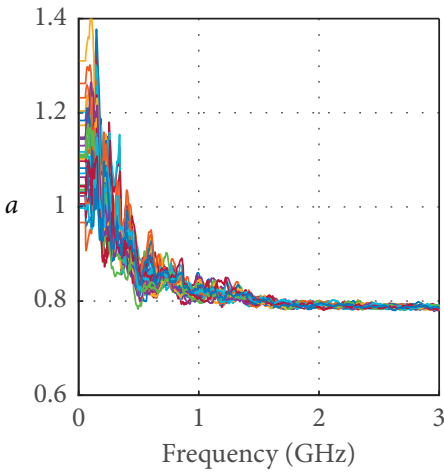

(h)

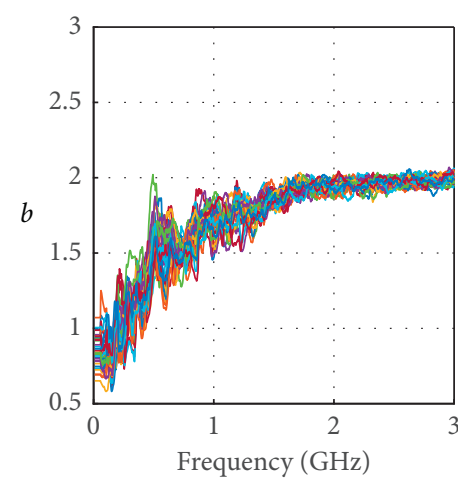

(k)

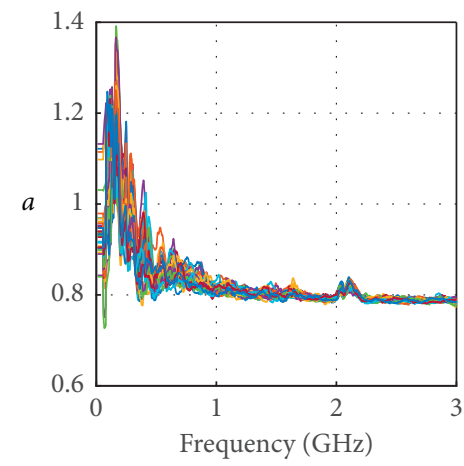

(c)

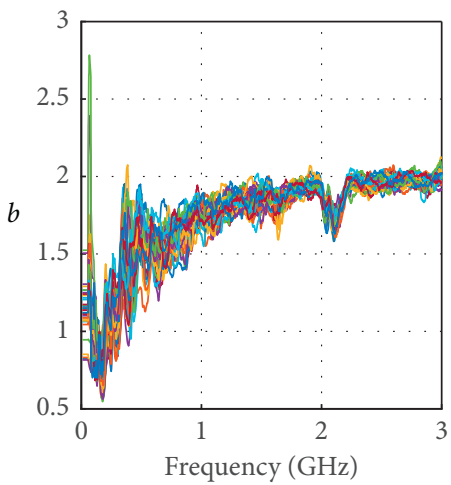

(f)

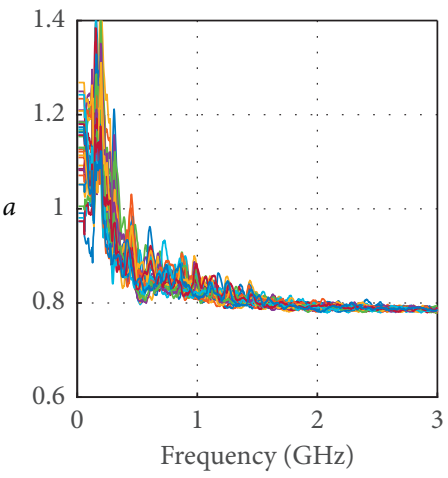

(i)

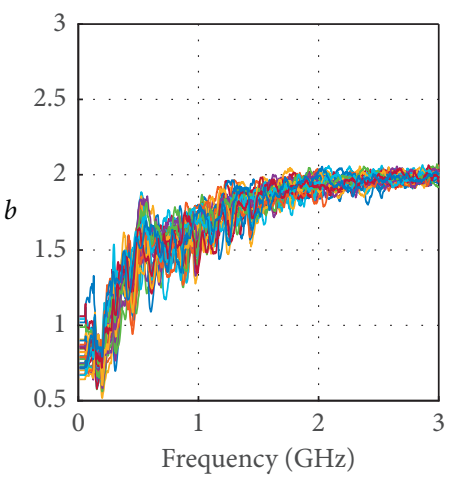

(l)

Figure 2: Continued. 


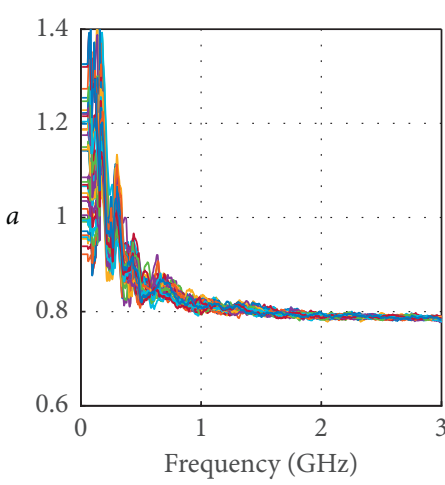

(m)

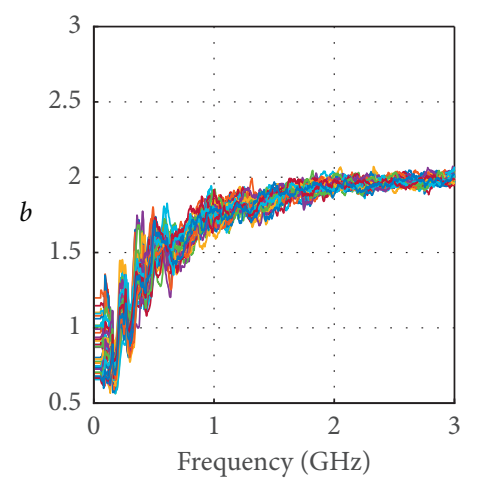

(p)

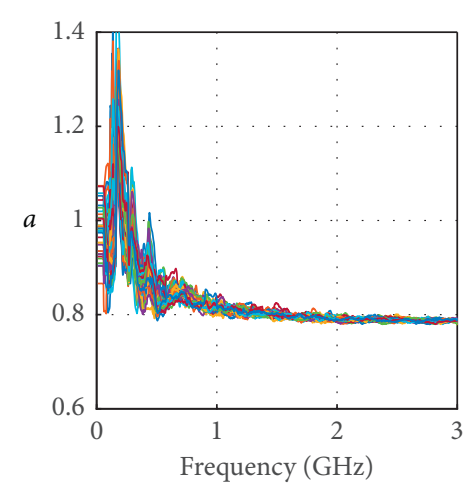

(n)

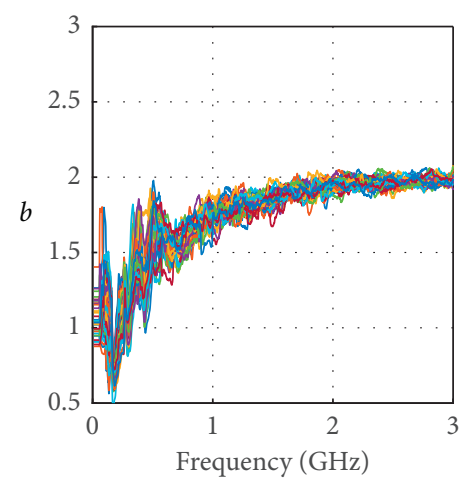

(q)

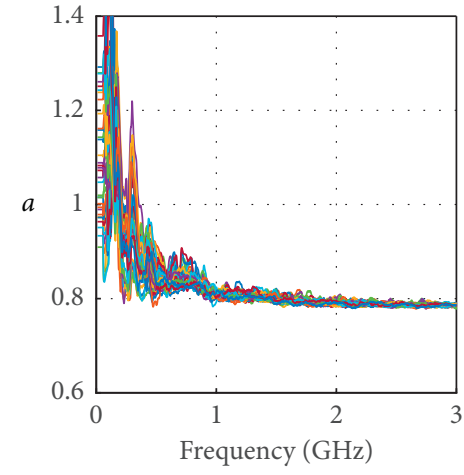

(o)

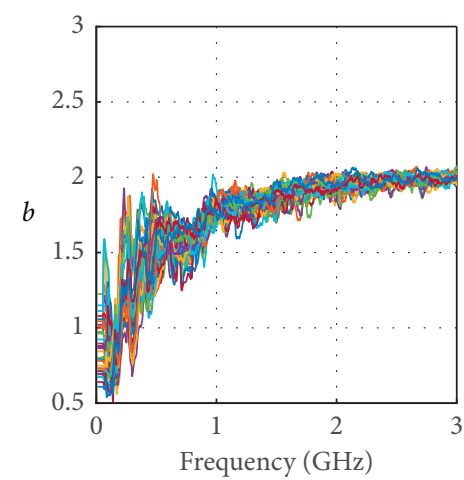

$(\mathrm{r})$

FiguRE 2: Estimated $(a, b)$ at different heights; 36 curves are overlaid. (a)-(f) are the estimated $(a, b)$ at the height of $30 \mathrm{~cm}$ for the $x$-polarized, $y$-polarized, and $z$-polarized probes, respectively; (g)-(l) are the estimated $(a, b)$ at the height of $62 \mathrm{~cm}$ for the $x$-polarized, $y$-polarized, and $z$ polarized probes, respectively; $(\mathrm{m})-(\mathrm{r})$ are the estimated $(a, b)$ at the height of $98 \mathrm{~cm}$ for the $x$-polarized, $y$-polarized, and $z$-polarized probes, respectively.

$$
\begin{array}{r}
N-a \sum_{i=1}^{N} x_{i}^{b}=0, \\
N+b \sum_{i=1}^{N} \ln x_{i}-a b \sum_{i=1}^{N} x_{i}^{b} \ln x_{i}=0,
\end{array}
$$

where the measured samples are $\left(x_{1}, x_{2}, \ldots, x_{N}\right)$ and $N$ is the sample number.

The random variable $X$ in (1) can be the measured $\left|S_{21}\right|$ or $\left|S_{21}\right|^{2}$ [8]. In this paper, we use the measured $\left|S_{21}\right|$ which corresponds to the E-field magnitude distribution in an RC. The measurement setup is illustrated in Figure 1 [12]. Figure 1(a) shows the schematic plot of the measurement; the computer controls the rotation of the stirrer, the $X Y$ platform, and the frequency sweep of the vector network analyzer (VNA). For each position of antenna 2 (a probe antenna), $S$-parameters (1601 points, $10 \mathrm{MHz}-3 \mathrm{GHz}$ ) of 360 stirrer positions were recorded [12]. The measurement scenario is illustrated in Figure 1(b), and the measured sample points are plotted in Figure 1(c). The dimensions of the RC are $0.8 \mathrm{~m} \times 1.2 \mathrm{~m} \times 1.2 \mathrm{~m}$, and the lowest usable frequency is about $1 \mathrm{GHz}$ [12]. Sample points at three different heights were measured: $30 \mathrm{~cm}$, $62 \mathrm{~cm}$, and $98 \mathrm{~cm}$; this makes $3 \times 36=108$ positions of antenna 2. For each position, three polarizations were also measured. Typical measured scattering parameters $S_{21}$ are illustrated in Figure 1(d) with three polarizations. Because the radiation efficiency of transmitting and receiving antennas and the cavity transfer function are all small at low frequencies, $S_{21}$ show small values below $100 \mathrm{MHz}$. We have checked the variation of the insertion loss caused by the movement of the cable, which is lower than $0.2 \mathrm{~dB}$ at $3 \mathrm{GHz}$. Thus, the movement of the cable does not affect our results.

The Weibull distribution parameters $(a, b)$ for each position, and polarization can be obtained by applying the MLE method in (4), where the random variable $X$ is the measured normalized $\left|S_{21}\right|$ (normalize to the mean value). To increase the sample number, the frequency stirring is also used, where we use 50 nearest-frequency sample points in this paper. Since $50 / 1601 \approx 3.1 \%$ is very small, we can assume that the antenna performance is nearly constant in this narrow band; thus, the antenna performance will not affect the PDF of the measured $S$-parameters. At each frequency, we have $50 \times 360=18000$ sample points to estimate $(a, b)$. The normalized random variable $X$ can be written as

$$
X=\frac{\left|S_{21}-\left\langle S_{21}\right\rangle_{50 \times 360}\right|}{\left\langle\left|S_{21}-\left\langle S_{21}\right\rangle_{50 \times 360}\right|\right\rangle_{50 \times 360}},
$$

where $\langle\cdot\rangle_{50 \times 360}$ means the average of mechanical stirring and frequency stirring. 
(a)

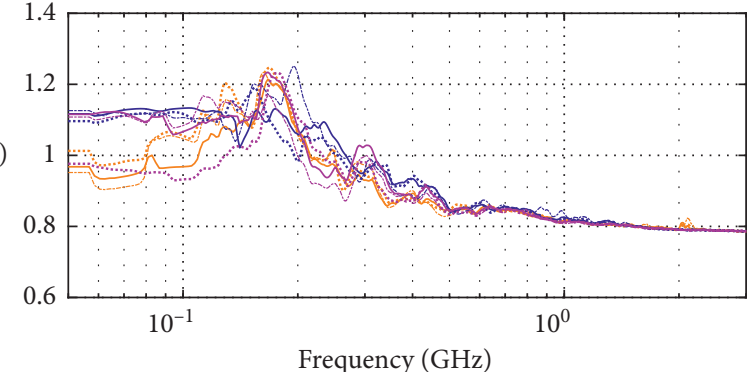

$-\mathrm{H}=30 \mathrm{~cm}, X$-polarized $\ldots-\mathrm{H}=62 \mathrm{~cm}, Z$-polarized $\mathrm{H}=30 \mathrm{~cm}, Y$-polarized $-\mathrm{H}=98 \mathrm{~cm}, X$-polarized

-. - $\mathrm{H}=30 \mathrm{~cm}, Z$-polarized $\quad \cdots . . \mathrm{H}=98 \mathrm{~cm}, Y$-polarized

$-\mathrm{H}=62 \mathrm{~cm}, X$-polarized $\quad \cdot-\cdot-\mathrm{H}=98 \mathrm{~cm}, Z$-polarized

… $\mathrm{H}=62 \mathrm{~cm}, Y$-polarized

(a)

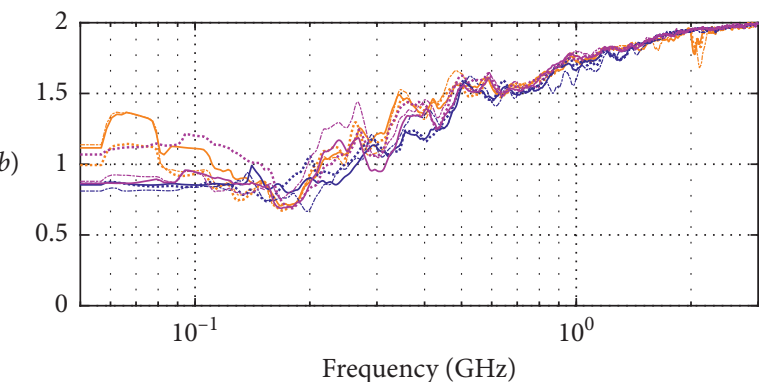

— $\mathrm{H}=30 \mathrm{~cm}, X$-polarized . . - $\mathrm{H}=62 \mathrm{~cm}, Z$-polarized $\mathrm{H}=30 \mathrm{~cm}, Y$-polarized $-\mathrm{H}=98 \mathrm{~cm}, X$-polarized

...- $\mathrm{H}=30 \mathrm{~cm}, Z$-polarized …. $\mathrm{H}=98 \mathrm{~cm}, Y$-polarized

— $\mathrm{H}=62 \mathrm{~cm}, X$-polarized . . - $\mathrm{H}=98 \mathrm{~cm}, Z$-polarized $\mathrm{H}=62 \mathrm{~cm}, Y$-polarized

(c)

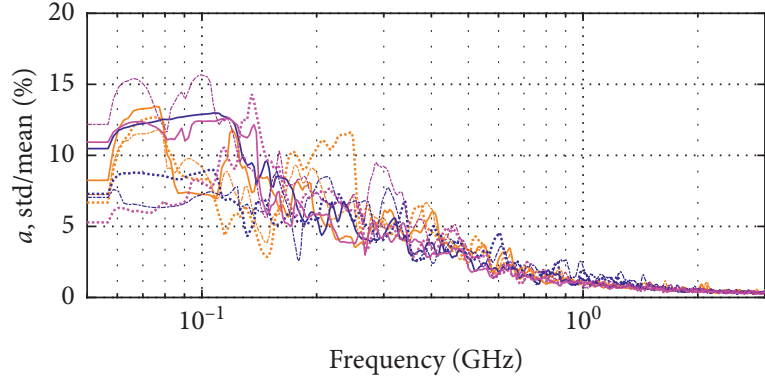

- $\mathrm{H}=30 \mathrm{~cm}, X$-polarized $\cdots \mathrm{H}=62 \mathrm{~cm}, Z$-polarized $\mathrm{H}=30 \mathrm{~cm}, Y$-polarized $-\mathrm{H}=98 \mathrm{~cm}, X$-polarized

... $\mathrm{H}=30 \mathrm{~cm}, Z$-polarized …. $\mathrm{H}=98 \mathrm{~cm}, Y$-polarized

- $\mathrm{H}=62 \mathrm{~cm}, X$-polarized . . - $\mathrm{H}=98 \mathrm{~cm}, Z$-polarized $\mathrm{H}=62 \mathrm{~cm}, Y$-polarized

(b)

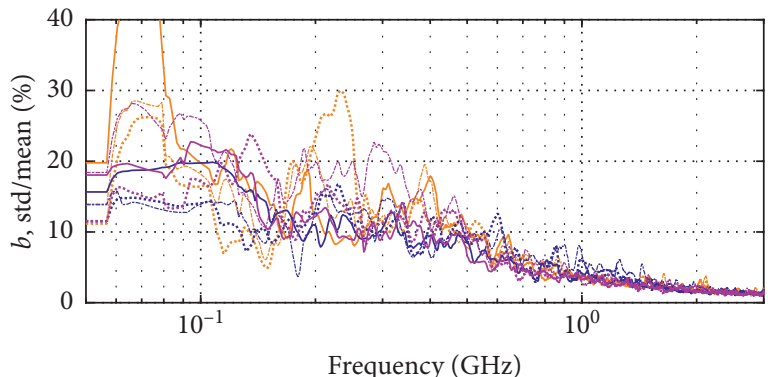

$\mathrm{H}=30 \mathrm{~cm}, X$-polarized … $\mathrm{H}=62 \mathrm{~cm}, Z$-polarized $\mathrm{H}=30 \mathrm{~cm}, Y$-polarized $-\mathrm{H}=98 \mathrm{~cm}, X$-polarized

. -. $\mathrm{H}=30 \mathrm{~cm}, Z$-polarized …... H $=98 \mathrm{~cm}, Y$-polarized

- $\mathrm{H}=62 \mathrm{~cm}, X$-polarized . . - $\mathrm{H}=98 \mathrm{~cm}, Z$-polarized $\mathrm{H}=62 \mathrm{~cm}, Y$-polarized

(d)

Figure 3: Mean values and the relative standard deviation (in percentage) of the estimated $(a, b)$ at different heights and polarizations.

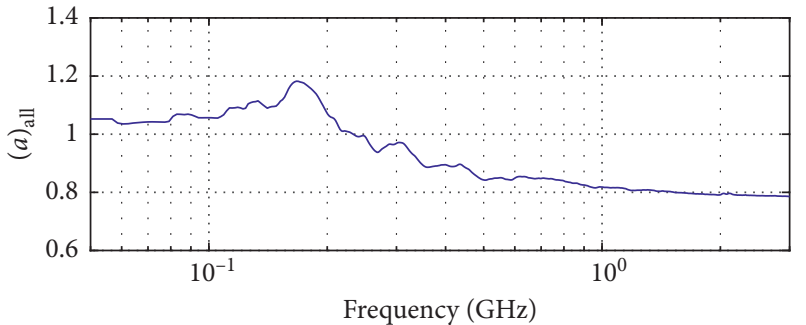

(a)

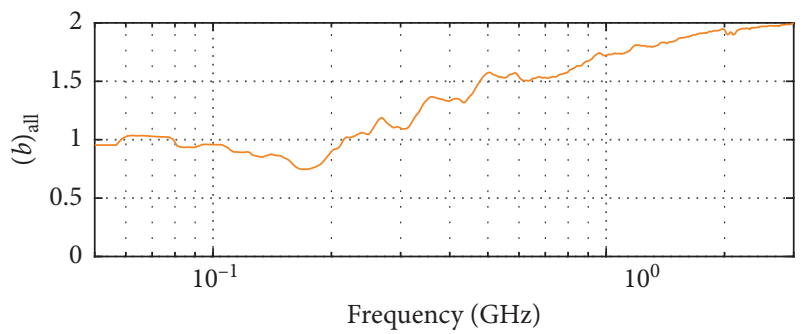

(c)

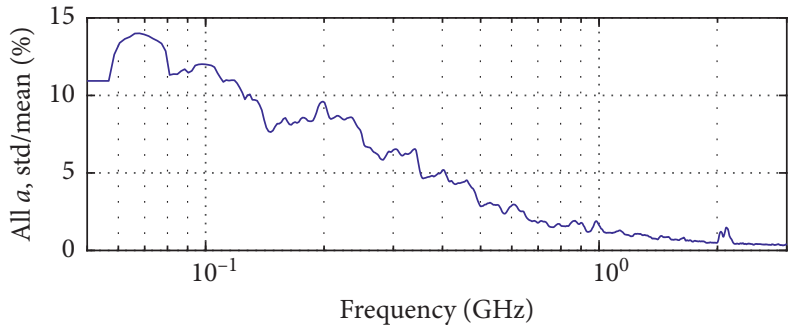

(b)

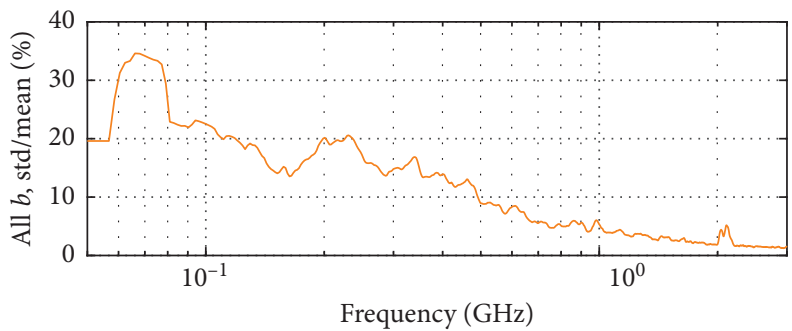

(d)

Figure 4: Mean values and the relative standard deviation (in percentage) of the estimated $(a, b)$; values for all positions and polarizations are used. 


\section{Measurement Results}

Since the Weibull distribution has been verified in the undermoded region [7-11], we do not repeat the hypothesis test for the Weibull distribution but focus on the estimated parameters $(a, b)$. For each position and polarization of antenna 2 , we can estimate $(a, b)$ as a function of frequency. The results are presented in Figure 2. 36 curves are overlaid for each height of antenna 2 . It is interesting to note that although the estimated parameters show dependencies on the position/polarization, the variations are not sensitive and have very similar shapes. Not surprisingly, when the frequency increases, $a \longrightarrow \pi / 4$ and $b \longrightarrow 2$, so the Weibull distribution reduces to Rayleigh distribution.

To quantify the statistical behavior of the estimated parameters, the mean values and the relative standard deviations (RSDs) for different heights and polarizations are illustrated in Figure 3 . To have a better resolution, the $x$-axis is plotted in the logarithmic scale. Note that the mean values are relatively stable and the RSDs are also small. Figure 4 presents the mean values and the RSDs of the estimated $(a, b)$ including all the positions and polarizations; also note that the RSDs are relatively small.

\section{Discussion and Conclusions}

To investigate the parameter stability of the Weibull distribution, we have adopted very fine measurements. 108 positions with three polarizations have been measured with 360 stirrer positions. The measurement results show that the parameters for the Weibull distribution are quite stable in the undermoded region and the statistical variation can be experimentally quantified.

Although the Weibull distribution model is valid in a wide frequency range, we have to note that the parameters have uncertainties. In the uncertainty analysis, we have to consider the uncertainties from two sources: (1) the estimated mean value (the FU definition in [1]); (2) the uncertainties from the distribution model parameters. Note that the mean value of Weibull distribution in (1) is

$$
\int_{0}^{\infty} a b x^{b} \exp \left(-a x^{b}\right) d x=\frac{\Gamma\left(b^{-1}\right)}{b a^{1 / b}}
$$

and we have normalized the samples to the mean value. Parameters $a$ and $b$ are actually not independent. Figure 5 shows the mean value of the estimated Weibull distribution for the measured $3 \times 108=324$ scenarios (including three polarizations for each antenna position), which also means that $a$ and $b$ are highly correlated.

We should note that although the Weibull distribution was found to be a good candidate to characterize the statistical behavior in the undermoded region, it may not be a unique one. There may exist other PDFs with more than two parameters to fit the undermoded region even better.

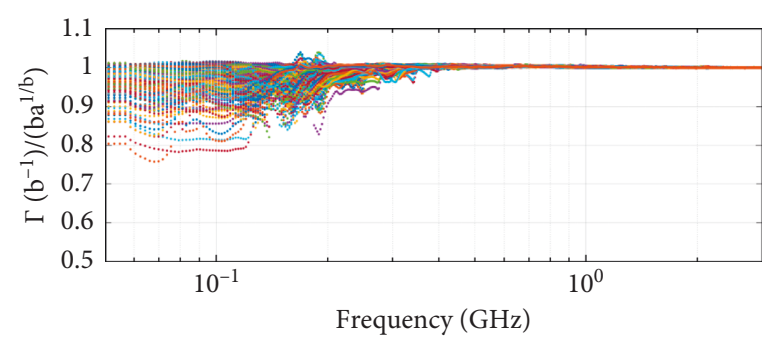

FIgURE 5: Calculated $\Gamma\left(b^{-1}\right) / b a^{1 / b}$ from the estimated $(a, b)$; points for 324 scenarios are illustrated with different colors.

\section{Data Availability}

The data used to support this study are available from the corresponding author upon request.

\section{Conflicts of Interest}

The authors declare that there are no conflicts of interest regarding the publication of this paper.

\section{Acknowledgments}

This work was supported in part by the National Natural Science Foundation of China under Grant 61701224.

\section{References}

[1] IEC 61000-4-21, Electromagnetic Compatibility (EMC)-Part 4-21: Testing and Measurement Techniques-Reverberation Chamber Test Methods, IEC Standard, Geneva, Switzerland, 2011.

[2] D. A. Hill, Electromagnetic Fields in Cavities: Deterministic and Statistical Theories, Wiley-IEEE Press, Hoboken, NJ, USA, 2009.

[3] P. Besnier and B. Demoulin, Electromagnetic Reverberation Chambers, Wiley-ISTE, Hoboken, NJ, USA, 2011.

[4] X. Chen, Reverberation Chamber Characterizations for Passive and Active OTA Measurements, Licentiate of Engineering thesis, Department of Signals and Systems, Chalmers University of Technology, Göteborg, Sweden, 2010.

[5] X. Chen, "Experimental investigation and modeling of the throughput of a $2 \times 2$ closed-loop MIMO system in a reverberation chamber," IEEE Transactions on Antennas and Propagation, vol. 62, no. 9, pp. 4832-4835, 2014.

[6] CTIA, "Test plane for wireless large-form-factor device over-the-air performance," CTIA, Washington, DC, USA, 2017.

[7] C. F. Bunting, "Statistical characterization and the simulation of a reverberation chamber using finite-element techniques," IEEE Transactions on Electromagnetic Compatibility, vol. 44, no. 1, pp. 214-221, 2002.

[8] G. Orjubin, E. Richalot, S. Mengue, and O. Picon, "Statistical model of an undermoded reverberation chamber," IEEE Transactions on Electromagnetic Compatibility, vol. 48, no. 1, pp. $248-251,2006$.

[9] C. Lemoine, P. Besnier, and M. Drissi, "Investigation of reverberation chamber measurements through high-power goodness-of-fit tests," IEEE Transactions on Electromagnetic Compatibility, vol. 49, no. 4, pp. 745-755, 2007. 
[10] M. Qu, G. Lu, J. Lin, Y. Wang, and Y. Guan, “An investigation of statistical distribution properties in reverberation chamber," in Proceedings of the 2008 International Conference on Microwave and Millimeter Wave Technology, pp. 1435-1437, Nanjing, China, April 2008.

[11] W. Xue, X. Chen, and A. Zhang, "Investigation of automotive testing in a reverberation chamber," IET Microwaves, Antennas \& Propagation, vol. 4, no. 12, 2010.

[12] Q. Xu and Y. Huang, Anechoic and Reverberation Chambers: Theory, Design and Measurements, Wiley-IEEE, Hoboken, NJ, USA, 2019. 


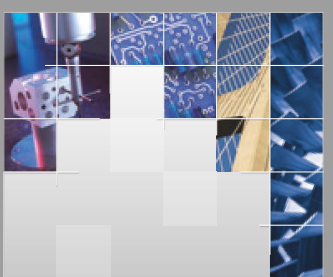

\section{Enfincering}
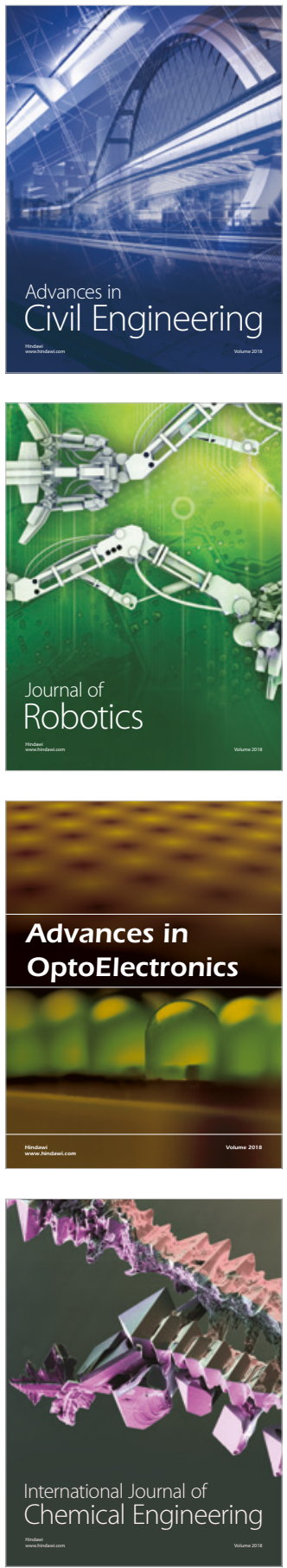

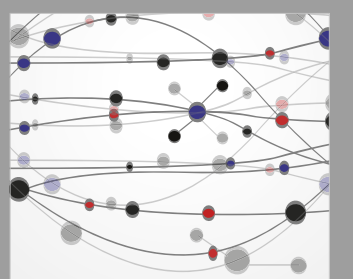

\section{Rotating \\ Machinery}

The Scientific World Journal

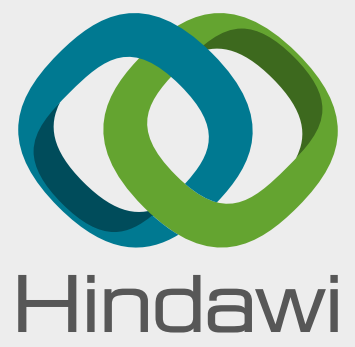

Submit your manuscripts at

www.hindawi.com
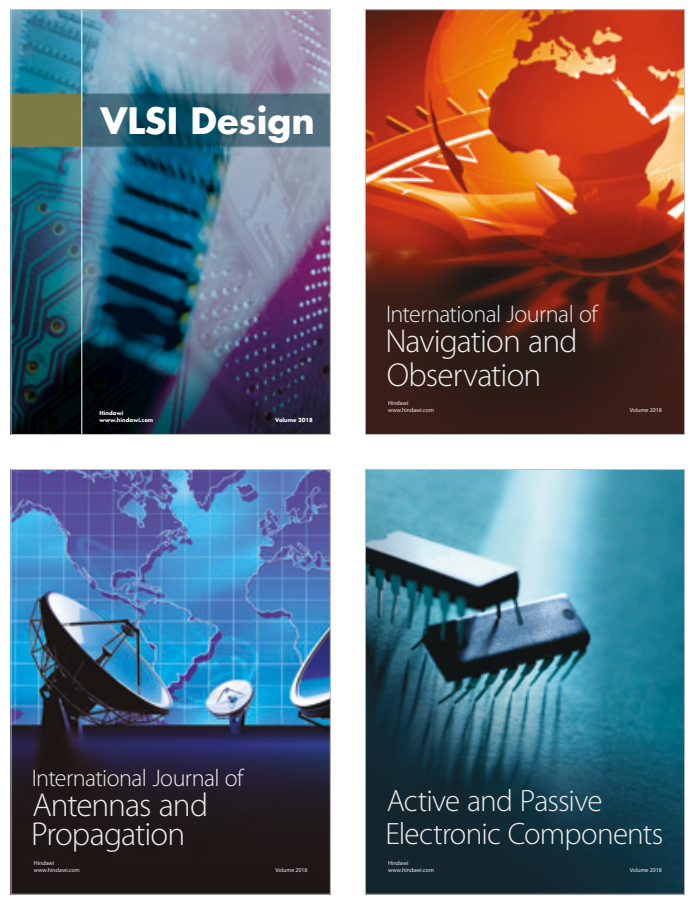
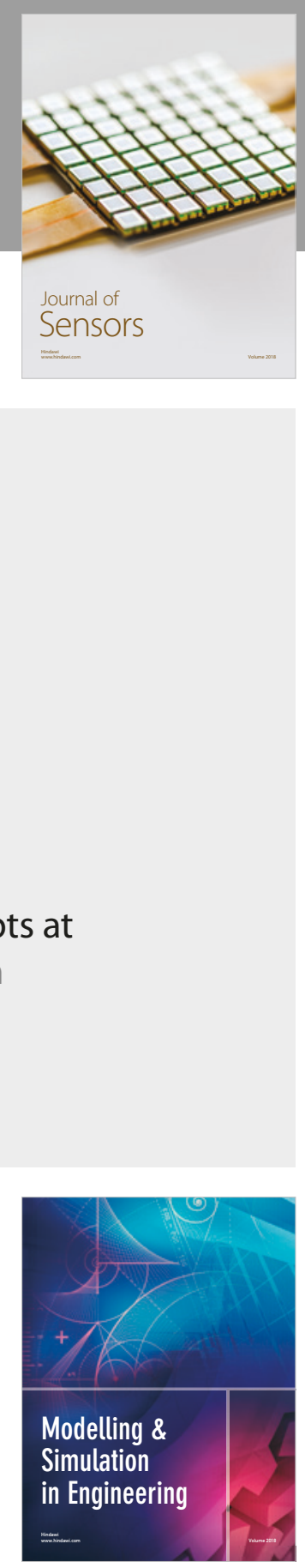

\section{Advances \\ Multimedia}
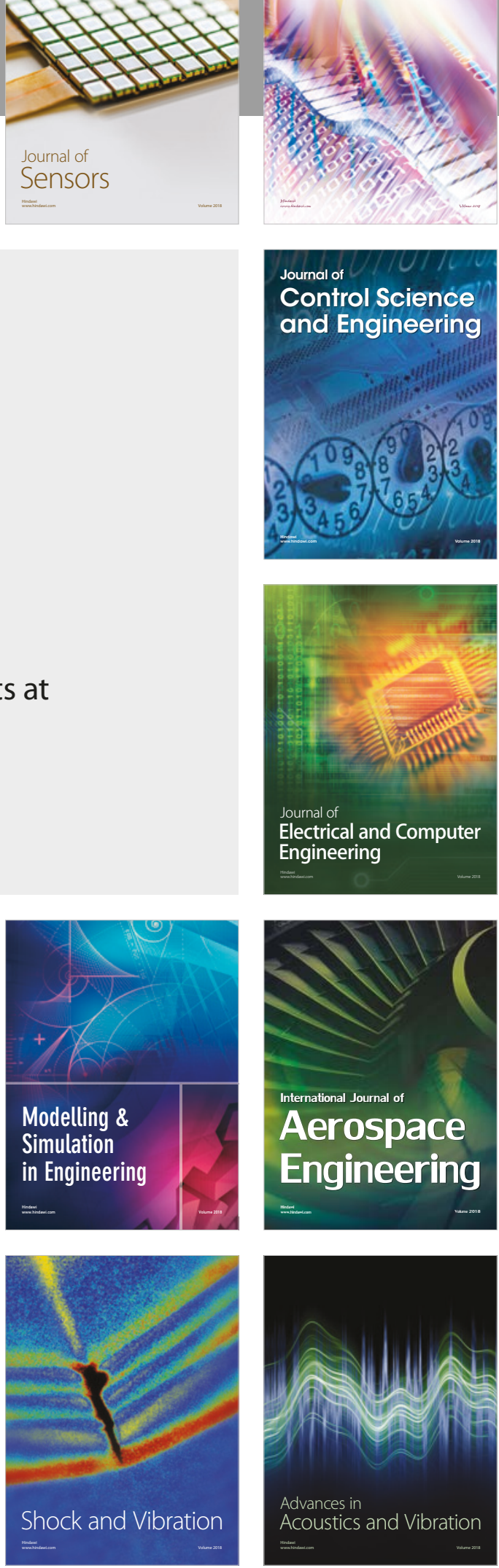